\title{
The prevalence rates of refractive errors among children, adolescents, and adults in Germany
}

\author{
Sandra Jobke' \\ Erich Kasten ${ }^{2}$ \\ Christian Vorwerk ${ }^{3}$ \\ 'Institute of Medical Psychology, \\ ${ }^{3}$ Department of Ophthalmology, \\ Otto-von Guericke-University of \\ Magdeburg, Magdeburg, Germany; \\ ${ }^{2}$ Institute of Medical Psychology, \\ University Hospital Schleswig- \\ Holstein, Luebeck, Germany
}

\begin{abstract}
Purpose: The prevalence rates of myopia vary between 5\% in Australian Aborigines to 84\% in Hong Kong and Taiwan, 30\% in Norwegian adults, and 49.5\% in Swedish schoolchildren. The aim of this study was to determine the prevalence of refractive errors in German children, adolescents, and adults.

Methods: The parents (aged 24-65 years) and their children ( 516 subjects aged 2-35 years) were asked to fill out a questionnaire about their refractive error and spectacle use. Emmetropia was defined as refractive status between $+0.25 \mathrm{D}$ and $-0.25 \mathrm{D}$. Myopia was characterized as $\leq-0.5 \mathrm{D}$ and hyperopia as $\geq+0.5 \mathrm{D}$. All information concerning refractive error were controlled by asking their opticians.
\end{abstract}

Results: The prevalence rates of myopia differed significantly between all investigated age groups: it was $0 \%$ in children aged $2-6$ years, $5.5 \%$ in children aged $7-11$ years, $21.0 \%$ in adolescents (aged $12-17$ years) and $41.3 \%$ in adults aged $18-35$ years (Pearson's Chi-square, $\mathrm{p}=0.000$ ). Furthermore, $9.8 \%$ of children aged $2-6$ years were hyperopic, $6.4 \%$ of children aged $7-11$ years, $3.7 \%$ of adolescents, and $2.9 \%$ of adults $(\mathrm{p}=0.380)$. The prevalence of myopia in females $(23.6 \%)$ was significantly higher than in males $(14.6 \%, \mathrm{p}=0.018)$. The difference between the self-reported and the refractive error reported by their opticians was very small and was not significant $(\mathrm{p}=0.850)$.

Conclusion: In Germany, the prevalence of myopia seems to be somewhat lower than in Asia and Europe. There are few comparable studies concerning the prevalence rates of hyperopia.

Keywords: Germany, hyperopia, incidence, myopia, prevalence

\section{Introduction}

A refractive error may be defined as a state in which the optical system of the nonaccommodating eye fails to bring parallel rays of light to focus on the retina. Especially myopia has become a very common problem. Several studies describe an increasing prevalence of myopia in the last two decades (Sveinsson 1982; Hosaka 1988; Fledelius 1983; Morgan and Munro 1973; Johnson et al 1984; van Rens 1991; Lin et al 2004; Rose et al 2001; Saw et al 2005) whereas other studies concluded that the frequency of myopia had been nearly static for a century (Midelfart et al 1992; Goldschmidt 2003; Fledelius 2000). Furthermore, racial differences in myopia rates are well documented. Prevalence of myopia has been shown to be as low as 2\% to 5\% in Australian Aborigines (Taylor 1981) and Salomon Islanders (Verlee 1968). Prevalence rates in Asian countries vary from $50 \%$ in Chinese children (Chung et al 1996) to $84 \%$ in Taiwan and Hong Kong (Lin et al 1996; Lam et al 2004).

In Europe, the prevalence of myopia seems to be lower than in Asian countries. The prevalence rates vary from $30.3 \%$ in middle-aged adults and $35.0 \%$ in young adults in Norway (Midelfart et al 2002) to 53\% in Norwegian medical students (Midelfart 
et al 1992). Guggenheim and colleagues (2003) reported a prevalence of myopia of $64 \%$ among British students between 18-40 years. Although this prevalence is supposed to be typical of university students (Loman et al 2002), the study was likely to have been affected by response bias, with more myopes choosing to participate than nonmyopes. A study of Mavracanas and colleagues (2000) have shown a prevalence of myopia of $36.8 \%$ among Greek students (aged 15-18 years).

In children, the prevalence of myopia varies from $9.2 \%$ among American children aged 5-17 years (Kleinstein et al 2003 ) to 6\% among 6-year-olds (Robinson 1999). Villareal and colleagues (2000) found a prevalence of $49.7 \%$ in Swedish school children aged 12-13 years.

The prevalence of hyperopia is not clear. The Eye Diseases Prevalence Research Group (2004) investigated persons older than 40 years and reported hyperopia rates of 9.9\% in America, 11.6\% in Western Europe and 5.8\% in Australia. Kleinstein and colleagues (2003) have shown a prevalence of hyperopia of $12.8 \%$ in American children aged 5-17 years. Midelfart and colleagues (2002) showed a prevalence of $13.2 \%$ among 20-25 year-olds and $17.4 \%$ among 40-45 year-olds. Wensor and colleagues (1999) have shown that more than every third person older than 40 years in Australia is hyperopic. Kinge and colleagues (1998) reported a prevalence of hyperopia of $47 \%$ among Norwegian adults.

The aim of this study was to determine the prevalence of refraction of the correcting glasses in children, adolescents, and adults in Germany.

\section{Participants and methods}

For the present study, the parents of children out of 7 kindergartens and 18 schools were invited to fill out a questionnaire. Furthermore, subjects aged 18 to 35 years were acquired in further education schools. The selection of the schools was randomized all over the area whereas all schools are public schools because in this area private schools are very seldom. Only schools with mentally disabled children were excluded from the selection. The selection of the schools cannot influence the generalisation of the results.

Parents of 536 subjects filled out the questionnaire, whereas 20 had to be excluded because of incomplete data (eg, missing date of birth etc.) or other reasons. The mean age of all subjects was $13.54 \pm 6.18$ years (range from 2-35 years). There were 219 (42.4\%) male and 297 (57.6\%) female subjects.
Before the parents filled out the questionnaire, they were aware that their answers and data could be checked. The questions concentrated on the children's and parent's refractive correction and their spectacle use, especially since when the subjects wore glasses and how long they used them each day. All information concerning the refraction of the correcting glasses was controlled by asking their opticians. The difference between the self-reported refraction and the refractive error reported by their opticians was very small and not significant $(p=0.850)$. The information given on the refractive correction seemed to be reliably correct. The refractive error was given as spherical equivalent (SE; sphere power +0.5 negative cylinder power). Emmetropia was defined as refractive status between $+0.25 \mathrm{D}$ and $-0.25 \mathrm{D}$. Myopia was characterized as $\leq-0.5 \mathrm{D}$ and hyperopia as $\geq+0.5 \mathrm{D}$. The chosen cutoff values for myopia ( $-0.5 \mathrm{D}$ or less) are common in the literature (Fledelius 1983; Wensor et al 1999; Negrel et al 2000; Midelfart et al 2002; Saw et al 2002; Guggenheim et al 2003; Fan et al 2004). Against this literature, Lin and colleagues (2004) defined myopia as $-0.25 \mathrm{D}$ or less and Kleinstein and colleagues (2003) have defined myopia as $-0.75 \mathrm{D}$ or less. Brody and colleagues (2007) graduated the definition between the age groups: in 3-4 year-olds myopia was defined as 2D or less and in children older than 4 years $1 \mathrm{D}$ or less. The cut-off criteria for hyperopia are not clear. Midelfart and colleagues (2002) and Wensor and colleagues (1999) defined hyperopia as $+0.5 \mathrm{D}$ or more whereas in the studies by Fan and colleagues (2004) and Saw and colleagues (2002) hyperopia was $+1.25 \mathrm{D}$ and more. Kleinstein and colleagues (2003) defined hyperopia as $+1.25 \mathrm{D}$ and more. Nearly all subjects could be clearly classified as myopic or hyperopic because both eyes had the same refractive status (either myopia or hyperopia). There was only one child whose right eye was emmetropic and whose left eye is myopic. This single case is assigned to the myopic group since the refraction of the correcting glasses of the left eye is $-1.0 \mathrm{D}$. Since the prevalence rates of astigmatism between the right and left eyes were similar, in the case of astigmatism only the right eye data are presented. All data are given as mean $\pm 1 \mathrm{SD}$.

None of the children underwent refractive surgery. If a subject wore contact lenses, the refractive power of the contact lenses was converted into the refractive power of glasses.

The statistical difference between the two groups was tested either with student's t-test (data are normally distributed) or Pearson's chi-square. Statistical analyses were conducted 
Table I The prevalence of myopia, emmetropia, and hyperopia for age groups 2-6 years, 7-II years, 12-17 years, and I8-35 years. Significant differences are given between male and female subjects

\begin{tabular}{|c|c|c|c|c|c|}
\hline Age group & $\mathrm{m} / \mathrm{f}$ & No. of subjects & Myopia & Emmetropia & Hyperopia \\
\hline & $\mathrm{m}$ & 36 & $0(0 \%)$ & $33(91.7 \%)$ & $3(8.3 \%)$ \\
\hline \multirow[t]{3}{*}{$2-6$ years } & $f$ & 46 & $0(0 \%)$ & $4 \mid$ (89.1\%) & 5 (10.9\%) \\
\hline & Total & 82 & $0(0 \%)$ & 74 (90.2\%) & $8(9.8 \%)$ \\
\hline & $\mathrm{m}$ & 54 & I (I.8\%) & 50 (92.6\%) & $3(5.6 \%)$ \\
\hline \multirow[t]{3}{*}{ 7-11 years } & $f$ & 56 & $5(8.9 \%)$ & 47 (83.9\%) & $4(7.2 \%)$ \\
\hline & Total & 110 & $6(5.5 \%)$ & 97 (88.1\%) & 7 (6.4\%) \\
\hline & $\mathrm{m}$ & 73 & $9(12.3 \%)^{*}$ & 58 (79.5\%) & $6(8.2 \%) *$ \\
\hline \multirow[t]{3}{*}{$12-17$ years } & $f$ & 113 & $30(26.5 \%)^{*}$ & $82(72.6 \%)$ & I $(0.9 \%)^{*}$ \\
\hline & Total & 186 & $39(21.0 \%)$ & 140 (75.3\%) & $7(3.7 \%)$ \\
\hline & $\mathrm{m}$ & 56 & $22(39.3 \%)$ & 32 (57.1\%) & $2(3.6 \%)$ \\
\hline \multirow[t]{3}{*}{ 18-35 years } & $f$ & 82 & 35 (42.7\%) & 45 (54.9\%) & $2(2.4 \%)$ \\
\hline & Total & 138 & 57 (4I.3\%) & 77 (55.8\%) & $4(2.9 \%)$ \\
\hline & Total & 516 & 102 (19.8\%) & 388 (75.2\%) & $26(5.0 \%)$ \\
\hline
\end{tabular}

Notes: *P $<0.05$; **P $<0.01$; ***P $<0.001 ; \mathrm{m}$, male; f, female.

using the commercially available statistical software, SPSS for Windows, version 13.0 (SPSS Inc., Chicago, IL).

\section{Results}

After exclusion of 20 questionnaires, 516 individuals were included in this study.

The prevalence rates of refractive errors based on $\pm 0.5 \mathrm{D}$ cut-off points in all age groups are presented in Table 1. The prevalence of myopia varied significantly between the four age groups, from $0 \%$ in the youngest group to $41.3 \%$ in the oldest group (Pearson's chi-square, $p=0.000$ ). The prevalence of myopia was greater in females than in males: $14.6 \%$ in males and $23.6 \%$ in females $(p=0.018)$.

The prevalence of hyperopia slightly decreased with age from $9.8 \%$ in the youngest age group to $2.9 \%$ in the oldest age group but did not vary significantly between the age groups. Furthermore, there was no significant gender difference in the prevalence of hyperopia $(\mathrm{p}=0.550)$, although the prevalence among male subjects was $7.5 \%$ and $5.7 \%$ among female subjects.

The mean spherical equivalent (SE) of all persons was $-1.06 \pm 2.54 \mathrm{D}$ (right eye) and $-1.09 \pm 2.49 \mathrm{D}$ (left eye), range from $-9.75 \mathrm{D}$ to $+7.25 \mathrm{D}$, turning from hyperopia to myopia from the age of 12 years and older (see Table 2). At the age of 6 years, there were 27 emmetropic ( 15 female and 12 male) and four hyperopic children (1 male and 3 female). The mean spherical equivalent in boys was $-0.54 \pm 2.72 \mathrm{D}$ (right eye) and $-0.70 \pm 2.64 \mathrm{D}$ (left eye) and in girls $-1.34 \pm$ $2.41 \mathrm{D}$ (right eye) and $-1.31 \pm 2.39 \mathrm{D}$ (left eye). This difference did not reach significance (student's t-test OD $p=0.087$, OS $\mathrm{p}=0.100$ ).

The prevalence of astigmatism in the spectacle wearers was $26.3 \%$ and there was no significant variance between the age groups ( $p=0.245$, see also Table 2$)$.

With regard to the ametropia onset, there were wide differences between myopia and hyperopia (see Figure 1). The mean age of myopia onset was $12.2 \pm 4.5$ years. In girls, myopia was diagnosed at age $11.7 \pm 4.6$ years and in boys at age $13.2 \pm 4.2$ years $(p=0.117)$. The incidence of myopia was nearly on the same level until age 9 years and then increased at the age of 10 years. The highest incidence of myopia was at the age of 15-16 years. Furthermore, 6 subjects became myopic after the age of 18 years. The incidence of hyperopia was highest from the age of one year to the age of 9 years.

Table 2 Mean refraction of the correcting glasses $( \pm S D)$ and prevalence of astigmatism of all spectacle wearers $(n=128)$ depending on the age group

\begin{tabular}{|c|c|c|c|c|}
\hline Age group & $\mathbf{n}$ & SE Right eye (D) & SE Left eye (D) & $\begin{array}{l}\text { Prevalence of } \\
\text { astigmatism }\end{array}$ \\
\hline $2-6$ years & 8 & $+2.81 \pm 2.49$ & $+3.16 \pm 2.34$ & $37.5 \%$ \\
\hline $7-11$ years & 13 & $+0.62 \pm 2.75$ & $+0.41 \pm 2.15$ & $15.4 \%$ \\
\hline $12-17$ years & 46 & $-1.20 \pm 2.13$ & $-1.23 \pm 2.21$ & $19.6 \%$ \\
\hline 18-35 years & 61 & $-1.82 \pm 2.20$ & $-1.85 \pm 2.10$ & $32.8 \%$ \\
\hline Total & 128 & $-1.06 \pm 2.54 D$ & $-1.09 \pm 2.49 D$ & $26.3 \%$ \\
\hline
\end{tabular}



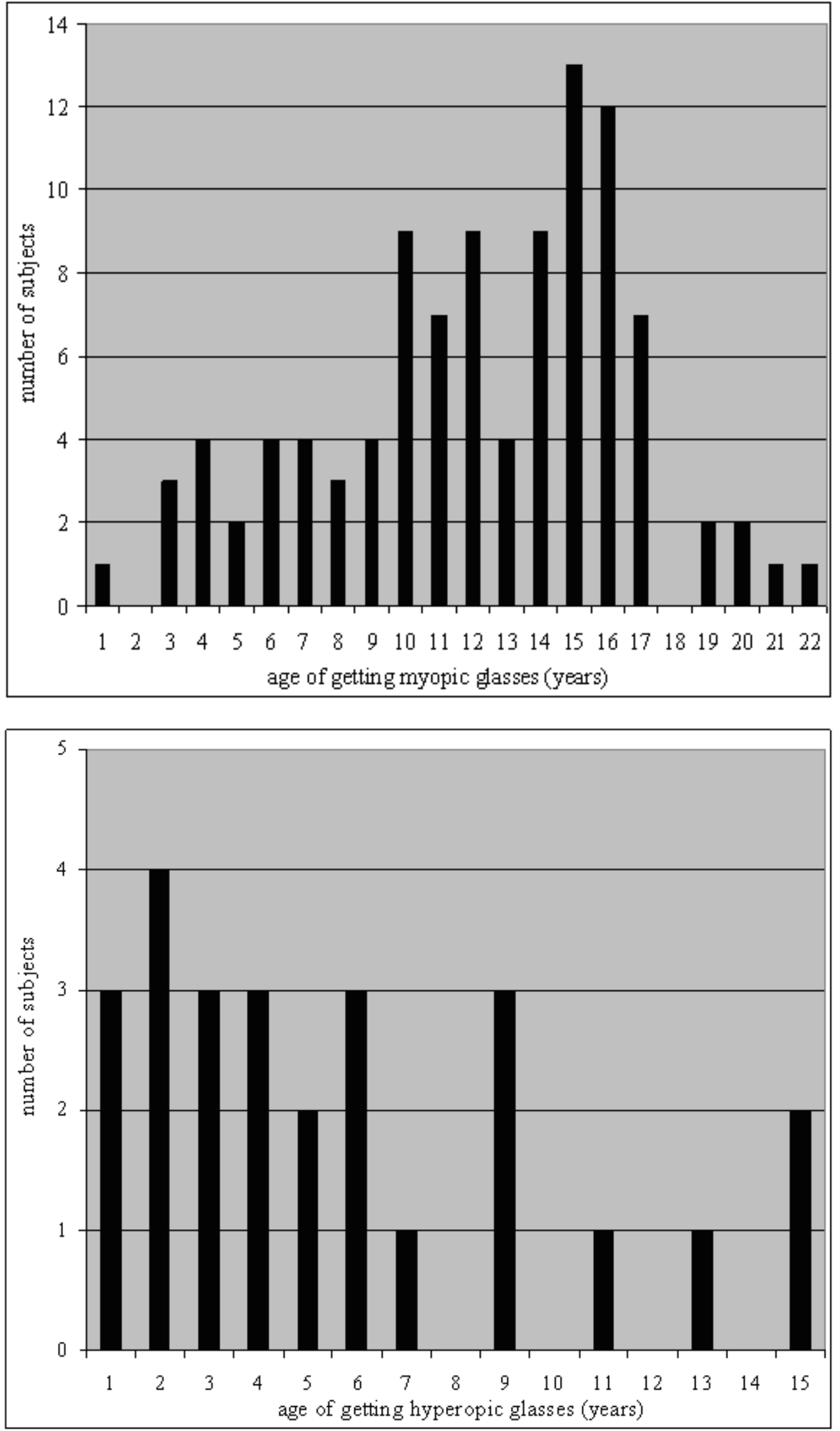

Figure I Age of getting glasses in years, A myopia (left), B hyperopia (right). 
Table 3 The prevalence of myopia, emmetropia, and hyperopia in the parents (only the refractive status for distance was surveyed, reading glasses are not evaluated)

\begin{tabular}{llllll}
\hline & No. of subjects & Myopia & Emmetropia & Hyperopia & Not applicable \\
\hline Fathers & 325 & $67(20.6 \%)$ & $206(63.4 \%)$ & $26(8.0 \%)$ & $26(8.0 \%)$ \\
Mothers & 456 & $118(25.9 \%)$ & $270(59.2 \%)$ & $37(8.1 \%)$ & $31(6.8 \%)$ \\
\hline
\end{tabular}

From the age of 10 years, there were only a few subjects ( 3 male, 1 female) becoming hyperopic. The mean age at which hyperopia was diagnosed was $5.7 \pm 4.2$ years. In case of hyperopia, there was no gender difference in age of onset: $5.2 \pm 4.2$ years in girls and $6.1 \pm 4.3$ years in boys.

Ten months after the first interview, 87 children (representing $16.9 \%$ of the original sample) were asked if they got a new prescription for their glasses in the meantime. Only three (already myopic) children $(0.6 \%)$ reported that they had new glasses. In these adolescents (aged 15-18 years) the myopia progressed by $-0.5 \mathrm{D}$.

The prevalence of myopia in the fathers was $20.6 \%$ and in mothers $25.9 \%$ (see Table 3 ). The prevalence of hyperopia did not vary between mothers $(8.1 \%)$ and fathers $(8.0 \%)$. The mean spherical equivalent in fathers was $-1.25 \pm 2.33 \mathrm{D}$ (right eye) and $-1.19 \pm 2.38 \mathrm{D}$ (left eye) and in mothers $-1.69 \pm$ $2.76 \mathrm{D}$ (right eye) and $-1.74 \pm 2.77 \mathrm{D}$ (left eye).

There was a high correlation between the spherical equivalent of the children with their parents' $(p=0.000)$. Furthermore there was a significant correlation between the age of myopia onset and the spherical equivalent in children $(p=0.000)$.

\section{Discussion}

Four groups of children (aged 2-6 years and 7-11 years), adolescents (aged 12-17 years) and adults (aged 18-35 years), were studied in order to examine the frequency of refractive errors in the general population in Germany.
The average prevalence of myopia in this study was $19.7 \%$. In age group 2-6 years of our sample, no child is myopic whereas Robinson (1999) found a prevalence of $6 \%$ in 6-year-olds. In children aged 7-11 years, a prevalence of myopia of $5.5 \%$ is shown which is much lower than Cummings (1996) who reported a prevalence of myopia of $24.4 \%$ in British children aged 8-10 years. In that study, there was no difference in prevalence between the 14-16-year-old age group, which suggests that myopia progression has reached the slow phase. But studies have also shown that myopia slows down after puberty (Rosenberg and Goldschmidt 1981; Mantyjarvi 1983).

A study by Mavracanas and colleagues (2000) have revealed a prevalence of myopia of $29 \%$ in Greek students aged 15-18 years which is somewhat higher than the prevalence found in this study $(21.0 \%)$ in the same age group. Villarreal and colleagues (2000) has revealed a prevalence of $49.7 \%$ in Swedish schoolchildren aged 12-13 years.

The highest myopia prevalence in this sample was found in subjects aged $18-35$ years $(41.3 \%)$. This is comparable with a study of Fledelius (2000) who has shown that every second person older than 18 years is myopic in Denmark. Midelfart and colleagues (2002) reported a prevalence of $35.0 \%$ in persons aged 20-25 years and a prevalence of $30.3 \%$ in persons aged $40-45$ years.

The Eye Diseases Prevalence Research Group (2004) investigated persons aged 40 years and older in Western Europe including Germany and found that $26.6 \%$ are myopic

Table 4 Prevalence of myopia and hyperopia from selected studies in Europe and the United States of America

\begin{tabular}{|c|c|c|c|c|c|}
\hline Study & Year & Where & Age (years) & Myopia & Hyperopia \\
\hline \multirow[t]{4}{*}{ Jobke et al } & 2008 & Germany & $2-6$ & $0 \%$ & $9.8 \%$ \\
\hline & & & $7-11$ & $5.5 \%$ & $6.4 \%$ \\
\hline & & & $12-17$ & $21.0 \%$ & $3.7 \%$ \\
\hline & & & $18-35$ & $41.3 \%$ & $2.9 \%$ \\
\hline Robinson & 1999 & USA & 6 & $6 \%$ & - \\
\hline Cummings & 1996 & Great Britain & $8-10$ & $24.4 \%$ & $0.6 \%$ \\
\hline Mavracanas & 2000 & Greece & $15-18$ & $29.0 \%$ & - \\
\hline Villareal et al & 2000 & Sweden & $12-13$ & $49.7 \%$ & - \\
\hline \multirow[t]{2}{*}{ Midelfart et al } & 2002 & Norway & $20-25$ & $35.0 \%$ & $13.2 \%$ \\
\hline & & & $40-45$ & $30.3 \%$ & $17.4 \%$ \\
\hline Fledelius & 2000 & Denmark & $22-41$ & $50 \%$ & - \\
\hline \multirow[t]{2}{*}{ Kinge } & 1998 & Norway & 20.6 & $33 \%$ vs. & $47 \%$ vs. \\
\hline & & & & $47 \%$ students & $30 \%$ students \\
\hline
\end{tabular}


and $11.6 \%$ are hyperopic. These findings cannot be compared because in this study only persons aged 2-35 years were interviewed. Prevalence rates observed in different studies are summarized in Table 4.

The average prevalence of hyperopia decreases with age from $8.3 \%$ in the youngest age group to $3.0 \%$ in the oldest age group. The prevalence of hyperopia found in this study $(6.4 \%)$ is higher than that seen by Cummings $(0.6 \%$; Cummings 1996). In age group 18 years and older, the prevalence of hyperopia is $2.9 \%$ which is much lower than the prevalence found by Midelfart and colleagues (2002). A risk of this study is, of course, that children who would have needed a refractive correction could remain undetected because we only asked the refraction power of the glasses. Refractive errors in children may often pass undiagnosed for a long time, especially hyperopia. Thus, the prevalence of myopia and hyperopia is possibly underestimated in the present study. But, for getting reliable and correct information about refractive errors, the opticians of all subjects with glasses were asked to confirm. As already stated, the difference between the self-reported refraction and the refractive error reported by their opticians was very small and not significant. So, the authors conclude that the self-reported refractive errors are correct and reliable. Kaesmann-Kellner and Ruprecht (2000) investigated 12,192 preschoolers aged 6 years and found in $24.2 \%$ a reduced visual acuity in children not wearing spectacles but no causes for this reduced visual acuity are given.

The incidence of myopia in this study was highest between age 14-16 years. In cases of hyperopia, the incidence decreased after age 6 years. Lin and colleagues (1996) found that the incidence of myopia is highest between 11-13 years of age. Fan and colleagues (2004) reported a higher incidence rate at age 11 years in Hong Kong. In case of myopia, the age of onset was lower in girls than in boys although this difference was not significant. The question is whether myopia really "occurs" or if it is merely first noticed at this age in consideration of higher requirements in school. In hyperopia, there was no gender difference.

There was a significant correlation between the spherical equivalent of the children with their parents'. This relation can support the theory that the tendency towards myopia is genetically determined which was also proposed by Guggenheim and colleagues (2003).

Our study presents the first prevalence rates of myopia and hyperopia for the age groups 2-35 years in Germany. Although the prevalence rates found in this study may be underestimated, and a comparison between all studies concerning the prevalence rates of myopia is not easy due to the variability in definition and selection of subjects, the prevalence rates found in this study are comparable with those found in other European studies (see Table 4). Altogether, the prevalence of myopia in Europe is much lower than in Asia (Lam et al 2004; Lin et al 1996, 2004) and has not reached alarmingly high prevalence rates. There are few comparable studies concerning the prevalence rates of hyperopia.

\section{References}

Brody BL, Roch-Levecq AC, Klonoff-Cohen HS, et al. 2007. Refractive errors in low-income preschoolers. Ophthalmic Epidemiol, 14:223-9.

Chung KM, Mohidin N, Yeow PT, et al. 1996. Prevalence of visual disorders in Chinese schoolchildren. 1996. Optom Vis Sci, 73:695-700.

Cummings GE. 1996. Vision screening in junior schools. Public Health, 110:369-72.

Fan DSP, Lam DSC, Lam RF, et al. 2004. Prevalence, incidence, and progression of myopia of school children in Hong Kong. IOVS, 45:1071-5.

Fledelius HC. 1983. Is myopia getting more frequent? A cross-sectional study of 1416 Danes aged 16 years. Acta Ophthalmol Scan, 61:545-59.

Fledelius HC. 2000. Myopia profile in Copenhagen medical students 1996-1998. Refractive stability over a century is suggested. Acta Ophthalmol Scand, 78:501-5.

Goldschmidt E. 2003. The mystery of myopia. Acta Ophthalmol Scand, $81: 431-6$

Guggenheim JA, Hill C, Yam TF. 2003. Myopia, genetics, and ambient lighting at night in a UK sample. Br J Ophthalmol, 87:580-2.

Hosaka A. 1988. Population studies: myopia experience in Japan. Acta Ophthalmol Suppl, 185:37-40.

Johnson GJ, Green JS, Paterson GD, et al. 1984. Survey of ophthalmic conditions in a Labrador community, II. Can J Ophthalmol, 19:224-33.

Kaesmann-Kellner B, Ruprecht KW. 2000. Vision screening survey of all children starting primary school in 1998 in the Federal State of Saarland, Germany. Strabismus, 8:201-7.

Kinge B, Midelfart A, Jacobsen G. 1998. Refractive errors among young and university students in Norway. Acta Ophthalmol Scand, 76:692-5.

Kleinstein RN, Jones LA, Hullett S, et al. Refractive error and ethnicity in children. 2003. Arch Ophthalmol, 121:1141-7.

Lam CSY, Goldschmidt E, Edwards MH. 2004. Prevalence of myopia in local and international schools in Hong Kong. Optom Vis Sci, $81: 317-22$.

Lin LLK, Shih YF, Hsiao CK, et al. 2004. Prevalence of myopia in Taiwanese schoolchildren: 1983 to 2000. Ann Acad Med Singapore, 33:27-33.

Lin LLK, Shih YF, Lee YC, et al. 1996. Changes in ocular refraction and its components among medical students. A 5-year-longitudinal study. Optom Vis Sci, 73:495-8.

Loman J, Quinn GE, Kamoun L, et al. 2002. Darkness and near work. Myopia and its progression in third-year law students. 2002. Ophthalmol, 109:1032-8.

Mantyjarvi M. 1983. Incidence of myopia in a population of Finnish school children. 1983. Acta Ophthalmol (Copenh), 61:417-23.

Mavracanas TA, Mandalos A, Peios D, et al. 2000. Prevalence of myopia in a sample of Greek students. 2000. Acta Ophthalmol Scand, 78:656-9.

Midelfart A, Aamo B, Sjöhaug KA, et al. 1992. Myopia among medical students in Norway. Acta Ophthalmol Scand, 70:317-22.

Midelfart A, Kinge B, Midelfart S, et al. 2002. Prevalence of refractive errors in young and middle-aged adults in Norway. Acta Ophthalmol Scand, 80:501-5. 
Morgan RW, Munro M. 1973. Refractive problems in northern natives. Can J Ophthalmol, 8:226-8.

Negrel AD, Maul E, Pokharel GP, et al. 2000. Refractive error study in children: Sampling and measurement methods for a multi-country study. Am J Ophthalmol, 129:421-6.

Robinson B. 1999. Factors associated with the prevalence of myopia in 6-year-olds. Optom Vis Sci, 76:266-71.

Rose K, Smith W, Morgan I, et al. 2001. The increasing prevalence of myopia: Implications for Australia. Clin Exp Ophthalmol, 29:116-20.

Rosenberg T, Goldschmidt E. 1980. The onset and progression of myopia in Danish school children. In: Fledelius HC, Alsbirk PH, Goldschmidt EW, eds., Proceedings of the Third International Conference on Myopia, Copenhagen, August 24-27, 1980, The Hague: W. Junk, 1981: pp. 33-9.

Saw SM, Tong L, Chua WH, et al. 2005. Incidence and progression of myopia in Singaporean school children. IOVS, 46:51-7.
Sveinsson K. 1982. The refraction of Icelanders. Acta Ophthalmol (Copenh), 60:779-87.

Taylor HR. 1981. Racial variations in vision. Am J Epidemiol, 113:62-80.

The Eye Diseases Prevalence Research Group. 2004. The prevalence of refractive errors among adults in the United States, Western Europe, and Australia. Arch Ophthalmol, 122:495-505.

van Rens GH. 1991. Refractive error and axial length among Alaskan Eskimos. Acta Ophthalmol (Copenh), 69:27-32.

Verlee DL. 1968. Ophthalmic survey in the Salomon Islands. 1968. Am J Ophthalmol, 66:304-19.

Villarreal MG, Ohlsson J, Abrahamsson M, et al. 2000. Myopisation: The refractive tendency in teenagers. Prevalence of myopia among young teenagers in Sweden. Acta Ophthalmol Scand, 78:177-81.

Wensor M, McCarty CA, Taylor HR. 1999. Prevalence and risk factors of myopia in Victoria, Australia. Arch Ophthalmol, 117:658-63. 
